\title{
Microbial Ecology in Reef Sediments of Biscayne National Park
}

Introduction- Biscayne National Park (BNP), located in south Florida, is unique from other national parks because more than $95 \%$ of its 172,000 acres is located in the marine environment containing mangrove, seagrass, and coral reef ecosystems (http://www.nps. gov/bisc/pphtml/nature.html). Recent declines in offshore coral reef health and shifts in nearshore biological communities may be linked to the quality and/or quantity of ground- and surface-water input to the park as well as to other ecosystem stress factors, such as chemical and nutrient pollution, sea level rise, or increased sea surface temperatures (Wingard and others, 2003). A critical component of the coral reef ecosystem that is typically overlooked during scientific investigations of reef productivity and health is the bacterial communities attached to sediment surfaces as well as in the pore water of those sediments. These bacterial communities regulate the mineralization and cycling of organic matter and produce environments (reductive or oxidative) that control nutrient and trace element speciation and concentrations in pore water. The transfer or flux of these pore-water constituents into the overlying water column provides a source of nutrients and trace elements to higher trophic levels. The relatively high carbon and nutrient cycling and flux rates that occur in reef sediment systems, which are driven by bacteria, support the high gross primary productivity rates of coral reefs (Wild and others, 2005). Conducting scientific investigations on these microbial and geochemical processes will undoubtedly further the scientific understanding of the processes that influence the overall productivity and health of our Nation's coral reefs. The objectives of this project are to establish baseline data on (1) the abundance and productivity of microbial communities associated with pore water and reef sediments, and (2) dissolved trace metals and particulate

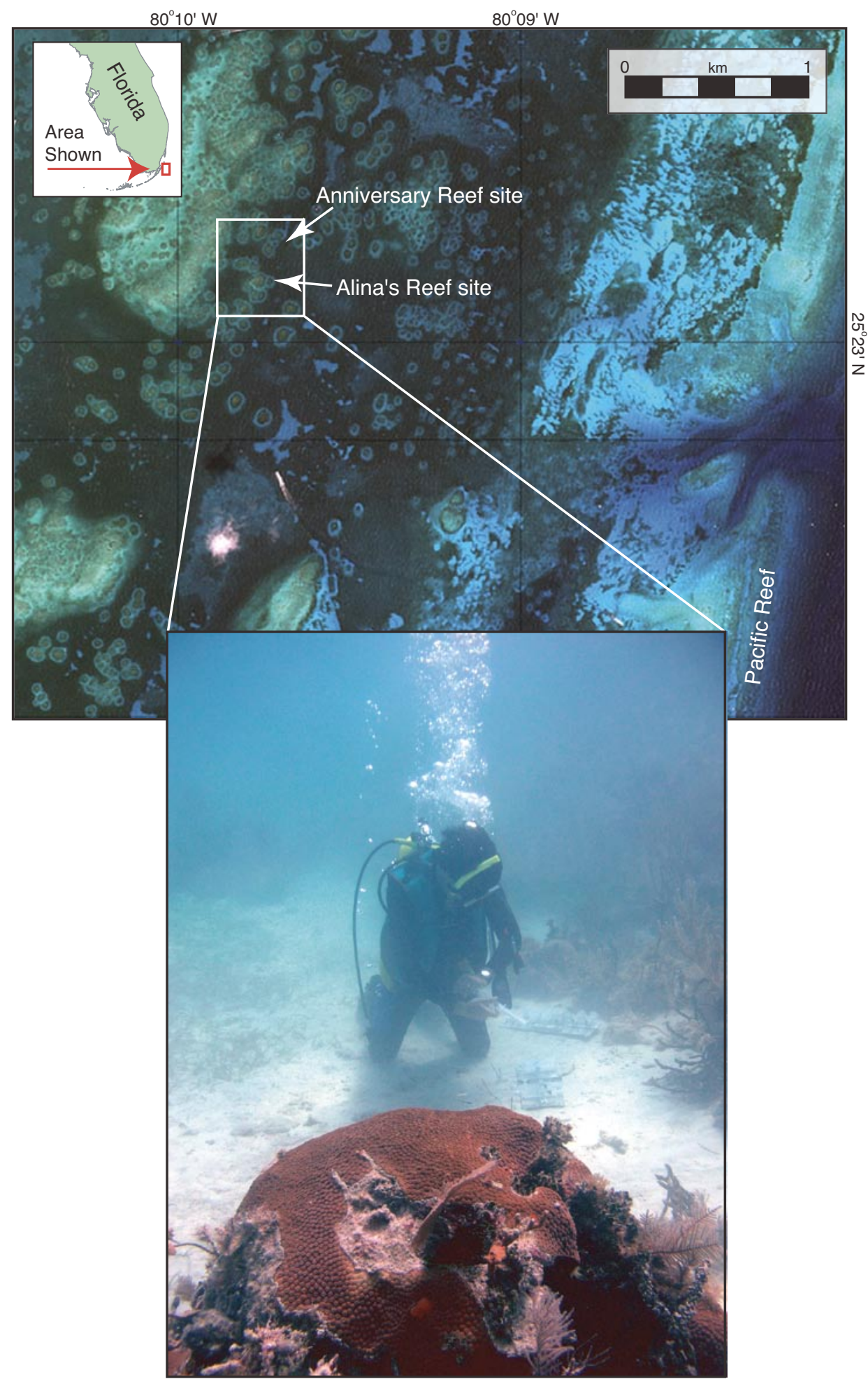

Figure 1. The sample sites for this study are located in the southeastern tip of Florida within Biscayne National Park. The two coral reef sites selected are Alina's and Anniversary Reefs, which are approximately 10 kilometers offshore. These reef systems are classified as patch reefs, with productive seagrass beds immediately outside the reef halo zone. 
and dissolved nutrients in surface and pore water and their respective flux rates at the boundaries of selected reefs in the Florida Keys.

Methods - Two sites, Alina's Reef and Anniversary Reef, were chosen based on previous investigations of in situ coral reef health (Yates and Halley, 2003; Fig. 1). The aim of this project is to establish baseline data on (1) the abundance and productivity of microbial communities associated with reef sediments and the pore water and (2) dissolved trace metals and particulate and dissolved nutrients in surface and pore water and their respective flux rates at the boundaries of selected reefs in the Florida Keys.
SCUBA divers collected pore-water samples from carbonate reef sediments at two depths, 1.3 and 12.7 centimeters $(\mathrm{cm})$. A round plate that can hold up to eight stainless steel samplers was used to stabilize the samplers at the two predetermined depths (Fig. 2 A, B). Each sampler has three slots at the tip that collect pore water at a vertical interval of $0.6 \mathrm{~cm}$. Five 60 -milliliter $(\mathrm{mL})$ precleaned and autoclaved syringes, tubing, and 3-way valves were used for each depth: two for microbiology samples, two for nutrient and trace metal samples, and one for field parameter analyses. A surface-water sample was collected from approximately $30 \mathrm{~cm}$ above the seafloor in a sterile 1-Liter bottle. In addition, a 2.5-cm-diameter, 16.3-cm-long core was collected from the adjacent reef sedi- ments (Fig 2 C, D). Once the divers and samples arrived in the boat, all pore and surface water samples were placed in coolers containing ice. The one syringe collected for field parameters (specific conductivity, temperature, $\mathrm{pH}$, and oxygen-reduction potential) was processed and analyzed immediately.

Determination of microbial productivity presents two challenges in this environment: (1) the methods routinely used to determine these rates require that the analyses be initiated almost immediately, which prohibits the preservation, prolonged storage or shipping of samples; and (2) an additional logistical problem of determining microbial productivity measurements in the field is the required use of radioisotope

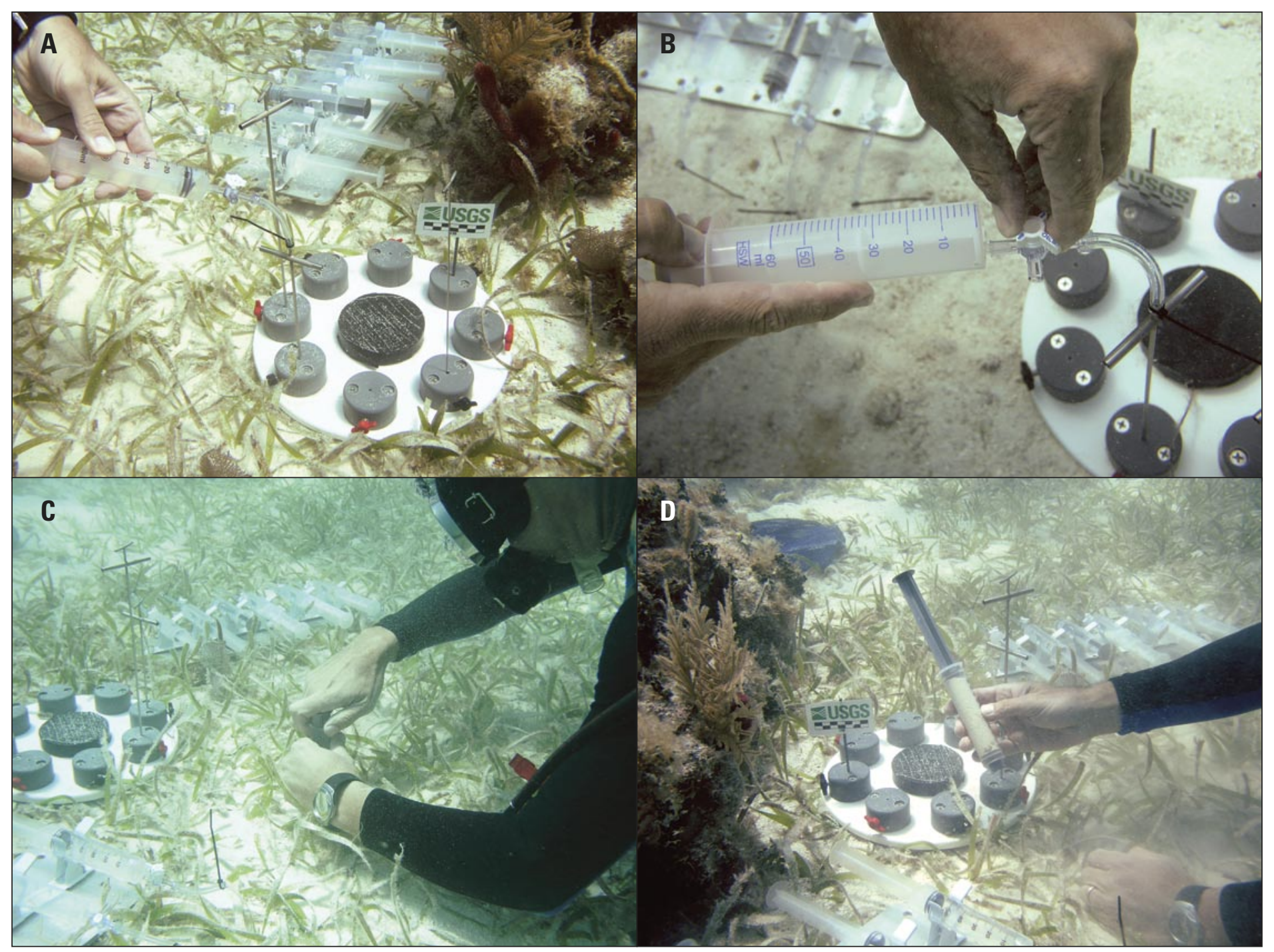

Figure 2. Sediment pore-water and core sampler. (A) Pore water sampling devices were inserted to predetermined depths below the under surface of the weighted plate and secured by thumb screws. Each pore-water sampler (M.H.E. Products, East Tawas, Michigan) is $0.3 \mathrm{~cm}$ in diameter and $35.6 \mathrm{~cm}$ in length with a sampling interval of $0.6 \mathrm{~cm}$. (B) Pore-water samples are collected by connecting a sterile $60 \mathrm{~mL}$ syringe, via tubing, to the pore-water sampler and gently extracting water samples from the predetermined sediment depths. (C,D) A sediment core $(2.5 \times 16.3 \mathrm{~cm})$ was collected using a modified $60 \mathrm{~mL}$ syringe that had the distal end removed. The core was contained by sliding a sterile plug into the open end of the coring device. 


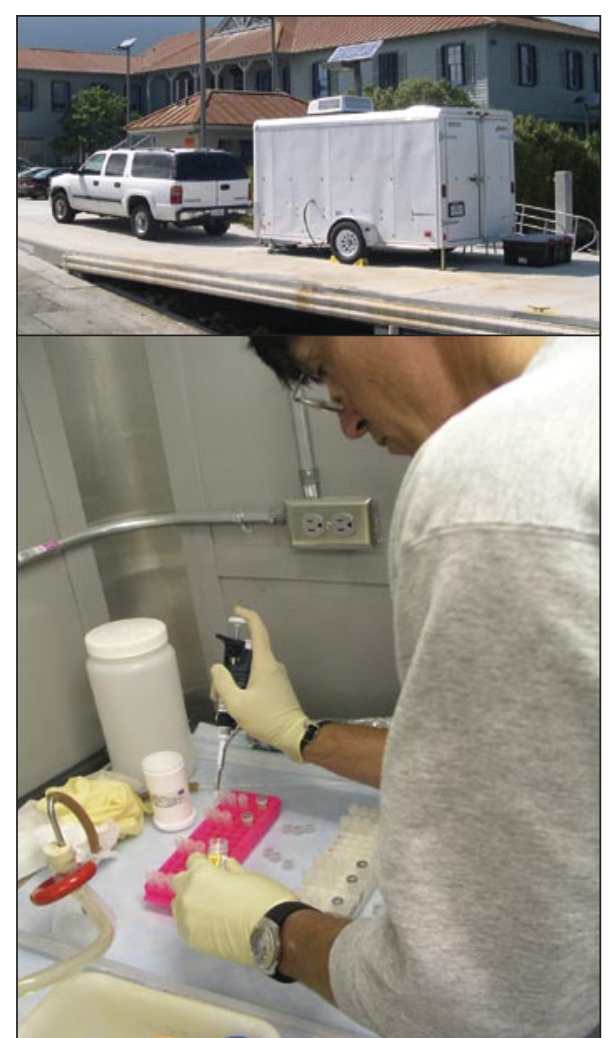

Figure 3. The USGS mobile field laboratory. Due to the requirement for rapid processing of samples, a mobile field laboratory was used to process and analyze the samples. The mobile laboratory is totally self-contained and powered, and easily transported and set up at field sites. One area of the mobile laboratory is designed for research that uses radioisotope-labeled substrates, which are necessary to determine the microbial ecology and productivity of coral reef systems. labeled substrates. Both of these issues have been addressed and these types of samples are processed less than 2 hours after collection using a mobile laboratory that has been USGS certified for use of radioactive isotopes (i.e., ${ }^{3} \mathrm{H},{ }^{14} \mathrm{C},{ }^{35} \mathrm{~S}$ ) in the field (Fig. 3).

Sediment samples initially were processed in the mobile laboratory to remove bacteria from the sediments. The remaining sediments were processed for particle size analysis and to determine the percentage of sand, silt and mud. Surface and pore water, and extracted sediment samples were then processed to determine bacterial productivity rates by adding ${ }^{3} \mathrm{H}$-leucine (a radiolabeled amino acid) to each sample, followed by a 1-hour incubation period. After termination of the assay the samples were processed to recover radiolabeled bacterial biomass. The radioactivity in each sample was then measured and recorded using a scintillation counter. The resulting data were used to calculate the bacterial productivity rates in the water ( $\left.\mu \mathrm{g} \mathrm{C} \mathrm{L}^{-1} \mathrm{~d}^{-1}\right)$ and sediment $\left(\mu \mathrm{g} \mathrm{C} \mathrm{g}^{-1} \mathrm{~d}^{-1}\right)$ samples.

Summary - Both reef sites had similar temperature profiles (Fig. 4). The $\mathrm{pH}$ profiles were also similar except for the March sample at Alina's Reef, when it dropped to 6.97 at $1.3 \mathrm{~cm}$. In general, the average $\mathrm{pH}$ of the pore water was 0.50 (range: 0.16-1.32) pH units lower than the overlying water column. This decrease in $\mathrm{pH}$ is significant in regard to the rates of dissolution and precipitation of carbonate sediments and how the concomitant increase in alkalinity may influence buffering in the overlying water column.

The oxygen-reduction potential data from both reefs followed a similar trend in that the sediment systems became more reduced as the water temperature increased (Fig. 4). The bacterial productivity rates in the sediment systems, which include pore water and sediments, also increased with increasing water temperature, with a 2 to 3 fold increase between the March and August sampling events (Fig. 4). On average, the bacterial productivity rates in the sediment systems were approximately 10 fold greater (range: 2.3-26.4 fold) than those measured in the overlying water column samples.

With regard to two nutrients that are important to coral reef productivity, ammonium $\left(\mathrm{NH}_{4}^{+}\right)$and silicate $\left(\mathrm{SiO}_{2}\right)$, their respective concentrations in the sediment systems are between 5 to 175 and 6 to 26 fold greater than in the water

\section{Alina's Reef}


Figure 4. Data summaries. The following datasets were collected from the overlying surface waters and two sediment depths at Alina's and Anniversary Reefs during three sampling events. (b.d. = below detection limit) 


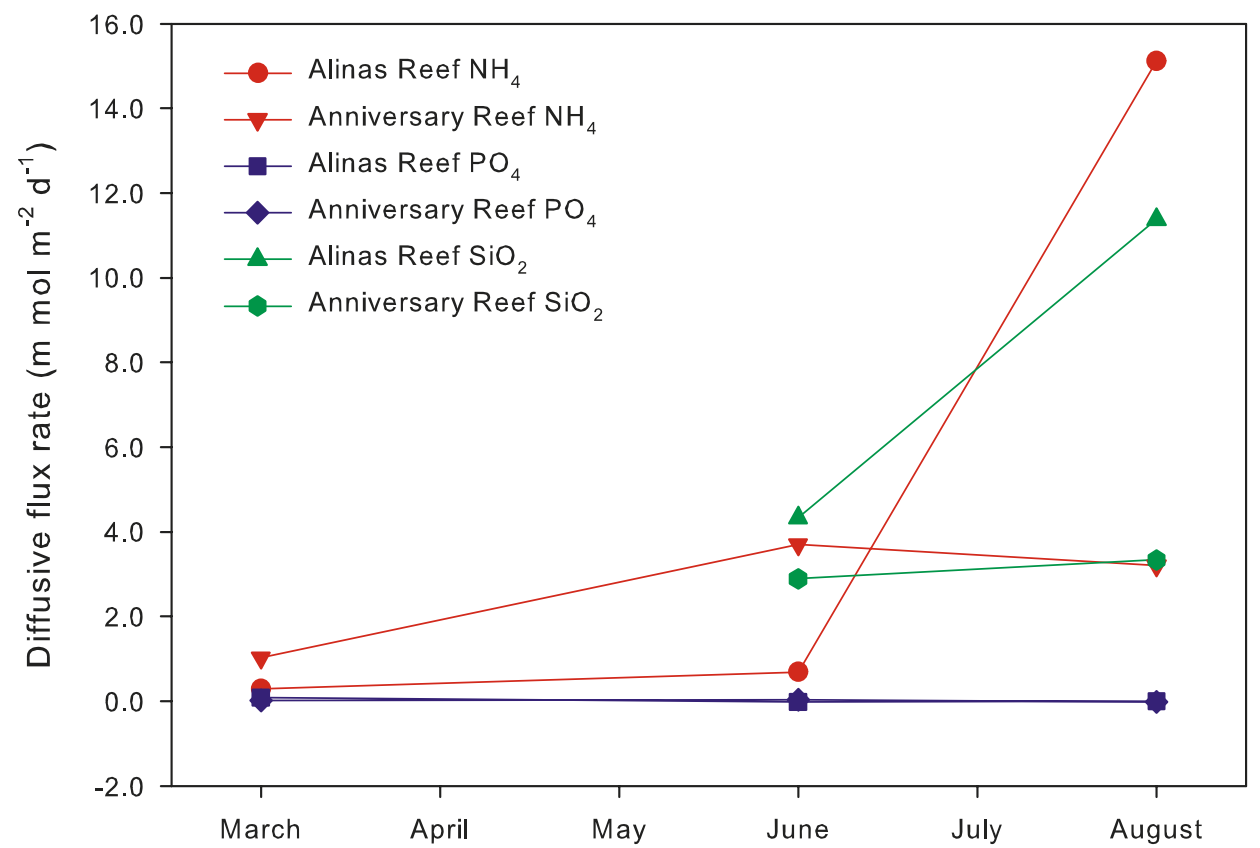

Figure 5. Diffusive flux rates of nutrients from the sediments. Nutrient concentration data from the overlying water columns and two sediment depths at Alina's and Anniversary Reefs were used to calculate diffusive flux rates of ammonium, silicate, and phosphate into the overlying water column.

columns adjacent to coral reefs. Accordingly, there was a flux of these nutrients from the sediments into the overlying water column at both reefs, with significant increases in the flux of ammonium and silicate at Alina's Reef between the June and August sampling events (Fig. 5). Flux rate estimates were calculated using Fick's law of diffusion and the appropriate constants as described by Rasheed and others, (2002). This approach to calculating flux rates does not account for advection, as described by Huettel and others, (1998). Therefore, the flux rate values from this study are conservative estimates.

Collectively, the data from this study show seasonal trends in the production and release of nutrients from sediments immediately adjacent to coral reefs. Bacterial activities directly alter sediment environments in ways that promote the production and cycling of these nutrients. The concentrations of these sedimentassociated nutrients are significantly greater than those found in the overlying water column and the flux rates of these nutrients contribute to the productivity of coral reefs. Bacterial cycling of carbon, nutrients, oxygen, and metals alters geochemical processes and, therefore, needs to be considered when assessing the ecology and health of coral reefs.

\section{Acknowledgments}

This project was funded by the USGS Coastal and Marine Program. We acknowledge Richard Curry (Biscayne National Park) for onsite logistical support and Molly McLaughlin (USGS) and Kate Ciembronowicz (USGS) for their assistance in the field. We also acknowledge Bob Halley (USGS) for constructive and informative conversations that assisted in the guidance of this research effort.

\section{References}

Huettel, M., Ziebis, W., Forster, S., and Luther III, G., 1998, Advective transport affecting metal and nutrient distributions and interfacial fluxes in permeable sediments: Geochimica et Cosmochimica Acta, v. 62, p. 613-631.

Rasheed, M., Mohammed, I., Richter, C., and Huettel, M., 2002, Effect of reef framework and bottom sediment on nutrient enrichment in a coral reef of the Gulf of Aqaba, Red Sea: Marine Ecology Progress Series, v. 239, p. 277-285.

Wild, C., Rasheed, M., Jantzen, C., Cook, P., Struck, U., Huettel, M., and Boetius, A., 2005, Benthic metabolism and degradation of natural particulate organic matter in carbonate and silicate reef sands of the northern Red Sea: Marine Ecology Progress Series, v. 298, p. 69-78.

Wingard, G., Cronin, T., Willard, D., Murray, J., Stamm, R., Holmes, C., Dwyer, G., Ishman, S., and Williams, C., 2003, Ecosystem history of central Biscayne Bay based on sediment core analyses: US Geological Survey Open-File Report 03-54, p 213-214.

Yates, K. and Halley, R., 2003, Measuring coral reef community metabolism using new benthic chamber technology: Coral Reefs, v. 22, p. 247-255.

alters geochemical processes, such as nutrient and metal cycling; (3) determining how different carbon and nutrient sources (e.g., phytoplankton biomass) from the overlying water column influences microbial productivity and nutrient cycling rates; and (4) how microbial activities in the sediments influence carbonate dissolution and precipitation in response to acidified pore water conditions.

\section{Contact Information:}

John Lisle, jlisle@usgs.gov

Chris Reich, creich@usgs.gov

600 4th Street South

St. Petersburg, FL 33701

727-803-8747 